\title{
Psychopathological and emotional deficits in myotonic dystrophy
}

\author{
C Bungener, R Jouvent, C Delaporte
}

\begin{abstract}
Objective-To evaluate psychopathological disturbances in patients with myotonic dystrophy (MD) and compare patients with MD to both patients with facioscapulohumeral dystrophy (FSHD) and healthy control subjects.

Methods-A semistructured interview was used to determine DSM III-R criteria for major depressive episodes, dysthymic episodes, and generalised anxiety. The Montgomery and Asberg and the Hamilton depressive scales, the Covi and Tyrer anxiety scales, the Abrams and Taylor scale for emotional blunting, and the depressive mood scale were all used in the study. Subjects were also asked to complete questionnaires for physical and social anhedonia.
\end{abstract}

Results-Fifteen patients with MD, 11 patients with FSHD, and 14 healthy subjects were studied. Patients with MD were not more depressed or anxious than healthy controls. Patients with FSHD were the most depressed and most anxious. However, patients with MD had significantly lower scores for expressiveness and significantly higher scores for anhedonia than the other two groups.

Conclusion-Patients with MD did not present significant depressive or anxious symptomatology but rather an emotional deficit. This emotional deficit may be an adaptive reaction to the threatening implications of the disease, or the effect of the CNS lesions which occur with MD, or both.

(F Neurol Neurosurg Psychiatry 1998;65:353-356)

Université de

Bourgogne, Dijon, France

C Bungener

Keywords: depression; emotional deficit; myotonic dystrophy

CNRS UMR 7395,

Hôpital de la

Salpêtrière, Paris,

France

C Bungener

$\mathrm{R}$ Jouvent

C Delaporte

Correspondence to:

Dr Catherine Bungener, CNRS UMR 7395, Hôpital

de la Salpêtrière, $47 \mathrm{Bd}$ de

l'Hôpital, 75013 Paris,

France. Telephone 0033144

2307 50; fax 003315370

07 70; email:

bungene@ext.jussieu.fr

Received 13 August 1997 and in final revised form 24 February 1998

Accepted 27 February 1998 cal aspects of the disease, concluded that patients were withdrawn and uncommunicative, that retardation correlated with the severity of the muscular pathology, and that patients showed a lack of energy, motivation, and commitment in a way which suggested that these were primary symptoms of the disease.

By the late 1930s, it was still uncertain whether emotional abnormalities were present in MD. Some authors claimed that MD was primarily a muscle disease, whereas others maintained that it was a neuropsychiatric condition originating in the brain stem. ${ }^{4}$ However, as Duveneck et $a \bar{l}$ noted later, very few of the early reports were based on firm psychological data.

The first studies designed to assess depressive symptomatology were by Brumback et $a l^{6}$ who found depression, assessed using the Hamilton depression rating scale (HDRS), to be an integral part of MD. Bird et al found high scores of depression on the Minnesota multiphasic personality inventory (MMPI) scale for $28 \%$ of their patients with MD. However, neither of these two studies included control groups.

Duveneck et al considered depression as secondary to the chronic progressive disease and refuted the hypothesis of Brumback et al that depression was a biological feature inherent to the $\mathrm{MD}$ disease process and in a later study ${ }^{8}$ they reported a high incidence of affective symptoms and in particular major depressive episodes. By contrast, Cuthill et at suggested that although depression might occur in patients with MD, most of their subjects were not depressed at the time of the study, suggesting that depression was seen as a reaction to the disease. Symptoms of anxiety were even less marked. Slowness, fatigability, poor self esteem, and irritability as a reaction to the impaired physical capacity were the common depressive symptoms. ${ }^{9}$ Others, ${ }^{10}$ however, reported that whereas the incidence of clinical depression may not have been high as previously reported, both typical and atypical depressive symptoms were a major feature of MD.

The study reported here is a comprehensive part of an overall investigation of personality, cognitive functions, and psychopathology in MD. It was designed to assess psychopathological disturbances, such as depression and anxiety, as well as emotional reactions, such as sadness, expressiveness, anhedonia, and irritability, found in patients with MD. Patients with MD were compared with two other groups: patients with facioscapulohumeral dystrophy (FSHD) and healthy subjects. FSHD was cho- 
Table 1 Demographic characteristics

\begin{tabular}{lllll}
\hline & $\begin{array}{l}\text { MD } \\
n=15\end{array}$ & $\begin{array}{l}\text { FSHD } \\
n=11\end{array}$ & $\begin{array}{l}\text { Controls } \\
n=14\end{array}$ & $\begin{array}{l}\text { ANOVA } \\
\text { p Value }\end{array}$ \\
\hline $\begin{array}{l}\text { Age (y): } \\
\text { Mean (SD) }\end{array}$ & $36.8(11.3)$ & $\begin{array}{l}33.2(8.3) \\
21-48\end{array}$ & $\begin{array}{l}35.7(13.3) \\
20-55\end{array}$ & 0.72 \\
$\quad \begin{array}{l}\text { Range } \\
\text { Sex (n (\%)): }\end{array}$ & $20-54$ & $4(36)$ & $5(36)$ & 0.99 \\
$\quad \begin{array}{l}\text { Men } \\
\text { Women }\end{array}$ & $5(33)$ & $7(64)$ & $9(64)$ & \\
$\begin{array}{l}\text { Education (y): } \\
\quad \text { Mean (SD) }\end{array}$ & $10(67)$ & $11.9(3.7)$ & $\begin{array}{l}13.9(2.7) \\
9-18\end{array}$ & 0.16 \\
$\quad$ Range & $11.6(3.5)$ & $6-17$ & & \\
\hline
\end{tabular}

sen to compare MD with a muscular disease not affecting the CNS.

\section{Subjects and methods}

PATIENTS

Fifteen patients with $M D, 11$ patients with FSHD, and 14 healthy controls were studied from January 1994 to December 1995. Subjects were matched for age, sex, and educational achievement.

Patients with MD and FSHD were outpatients at the neuromuscular department in a major teaching hospital in Paris (La PitiéSalpêtrière). Healthy controls were recruited from relatives of hospital staff.

All subjects came for a medical examination and, if they met the inclusion criteria, were asked to take part in a study. Informed written consent was obtained. The rater received preliminary training in the method of assessment and was blind to group membership.

Inclusion criteria for patients with MD were: age 20 to 40, no history of psychiatric illness, diagnosis of $\mathrm{MD}$ for no more than five years, with absent or very mild muscular weakness (stages 0,1 , or 2 according to the criteria of Mathieu et $a l^{11}$ ). Eight patients had minimal muscle weakness and had been diagnosed in the course of a routine check up. In two patients, cataracts were the presenting symptoms and in one woman the diagnosis had been made when she gave birth to a child with a congenital form of the disease. In 12 subjects the disease had been transmitted by the father, in two by the mother, and in one the transmission could not be established, although paternal transmission seemed likely. Congenital forms of MD were excluded. All patients had been diagnosed after the age of 17 .

The diagnosis of $\mathrm{MD}$ was made on the basis of a clinical examination, family history, EMG, and genetic analysis showing expanded CTG repeats (from 260 to 1000).

The patients with FSHD had no history of psychiatric or central nervous disease; all had minimal muscle weakness, using the same criteria as for patients with MD. ${ }^{11}$ The healthy controls had no history of muscular, neurological, or psychiatric disorders.

\section{ASSESSMENTS}

The affective state of all subjects was assessed using a semistructured interview lasting 45 minutes. At the end of the interview the subjects were asked to complete the anhedonia self questionnaires.
Psychopathology

Major depression, dysthymia, and anxiety disorders were diagnosed according to DSM III-R criteria. ${ }^{12}$ The Montgomery and Asberg depression rating scale (MADRS) (range $0-60),{ }^{13}$ the Hamilton depressive rating scale, 17 items (HDRS) (range $0-51),{ }^{14}$ the Covi brief anxiety scale (range $0-9$ ), ${ }^{15}$ the Tyrer anxiety scale (range $0-60$ ), ${ }^{16}$ the Abrams and Taylor scale for emotional blunting (AT) (range 0-30), ${ }^{17}$ and the depressive mood scale $(\mathrm{EHD})^{18}{ }^{19}$ were used in the study.

The depressive mood scale (EHD) is a 20 item scale with 10 items assessing emotional changes expressed by the patient and 10 items assessing the emotional state as perceived by the investigator observing the patient's facial reactions, speech, and motor expressiveness. Each item is rated from 0 (absent) to 4 (severe). The scale has a coherent factorial structure with five components: irritability, anhedonia, expressiveness, sadness, and affective hyperaesthesia. These five factors define two main dimensions: emotional deficit or blunted affect (combining anhedonia and hypoexpressiveness) and loss of control (combining irritability and hyperexpressiveness). The emotional deficit combines a lack of emotional initiation and reactivity, affective monotony, and anhedonia. The EHD scale has been validated for other neurological diseases. ${ }^{1920}$

\section{Anhedonia}

Recent studies have shown that anhedonia is part of depressive symptomatology. ${ }^{21}{ }^{22}$ Chapman $e t a l^{23}$ made the distinction between physical and social anhedonia. For the purposes of the present study, anhedonia was considered, from the patient's point of view, as an individual subjective appreciation of whether or not he or she was experiencing pleasure.

Anhedonia was assessed using two self rated questionnaires: the physical anhedonia scale (PAS) and the social anhedonia scale (SAS). ${ }^{23}$ Both questionnaires have been translated and validated in French. ${ }^{24} 25$

STATISTICAL ANALYSIS

Statistically significant differences $(p<0.05)$ were identified using analysis of variance (ANOVA). Fisher's test was used for one to one comparisons of the three groups.

\section{Results}

Demographic data on the three groups studied are detailed in table $1 ; 67 \%$ of patients with $\mathrm{MD}, 64 \%$ of patients with FSHD, and $64 \%$ of controls were women. Age, sex, and education levels were not significantly different for any of the three groups.

Table 2 gives the results of the psychopathological scales and anhedonia questionnaires. The muscle weakness of patients with MD showed three patients in stage 0,10 patients in stage 1 , and two patients in stage $2 .{ }^{11}$

DEPRESSION

One patient with MD met DSM III-R criteria for a major depressive episode, and two 
Table 2 Psychopathological scales

\begin{tabular}{|c|c|c|c|c|}
\hline & $\begin{array}{l}M D \text { mean } \\
(S D) n=15\end{array}$ & $\begin{array}{l}\text { FSHD mean } \\
\text { (SD) } n=11\end{array}$ & $\begin{array}{l}\text { Controls mean } \\
\text { (SD) } n=14\end{array}$ & p ANOVA \\
\hline \multicolumn{5}{|l|}{ Depression: } \\
\hline HDRS & $4.7(4.8)$ & $7.2(7.1) \ddagger$ & $1.9(1.6) \ddagger$ & 0.04 \\
\hline MADRS & $6.0(6.5)$ & $8.3(8.4) \ddagger$ & $1.9(1.7) \ddagger$ & 0.04 \\
\hline \multicolumn{5}{|l|}{ Anxiety: } \\
\hline Tyrer & $6.1(5.6)$ & $9.4(8.9) \ddagger$ & $3.5(2.4) \ddagger$ & 0.06 \\
\hline Covi & $1.6(1.9)$ & $2.5(3.1)$ & $1.1(1.1)$ & 0.31 \\
\hline $\begin{array}{l}\text { Abrams Taylor for emotional } \\
\text { blunting }\end{array}$ & $4.7(3.8)^{\star}+$ & $1.6(1.8)^{\star}$ & $0.8(1.8) \dagger$ & 0.002 \\
\hline \multicolumn{5}{|l|}{ Mood scale: } \\
\hline Emotional deficit & $6.7(5.4)^{\star} \dagger$ & $2.5(3.4)^{\star}$ & $1.6(2.5) \dagger$ & 0.004 \\
\hline Loss of control & $5.2(4.7)$ & $5.9(6.5)$ & $2.5(2.6)$ & 0.16 \\
\hline Irritability & $4.6(3.7)$ & $4.8(5.0)$ & $2.0(2.2)$ & 0.11 \\
\hline Anhedonia & $2.3(2.8)+$ & $1.4(2.3)$ & $0.4(0.9)+$ & 0.07 \\
\hline Expressiveness & $-3.9(4.3)^{\star}+$ & $0.1(2.5)^{\star}$ & $-0.8(2.1) \dagger$ & 0.007 \\
\hline Sadness & $2.1(1.5) t$ & $1.9(2.2)$ & $0.9(0.9) \dagger$ & 0.11 \\
\hline Anxious hyperaesthesia & $0.7(1.0)$ & $0.8(1.7)$ & $0.1(0.4)$ & 0.27 \\
\hline \multicolumn{5}{|l|}{ Anhedonia: } \\
\hline Physical & $20.5(11.4) \dagger$ & $17.8(8.8) \ddagger$ & $9.3(6.5) \dagger \ddagger$ & 0.008 \\
\hline Social & $12.3(7.2)$ & $12.8(7.5)^{\top}$ & $8.1(3.8)$ & 0.12 \\
\hline
\end{tabular}

patients with FSHD for a dysthymic episode. No subject in the control group met DSM III-R criteria.

Ratings of depression (HDRS and MADRS) were significantly different for the three groups $(\operatorname{MADRS}(F(2,39)=3.65 ; \mathrm{p}=0.04)$ and HDRS $(F(2,39)=3.66 ; \mathrm{p}=0.04))$. Patients with FSHD scored the highest but only differed significantly from control subjects (Fisher's test, $\mathrm{p}<0.05)$.

\section{ANXIETY}

No subjects met DSM III-R criteria for generalised anxiety. The Covi and Tyrer anxiety scales showed no significant difference between the three groups, although results for the Tyrer scale fell just short of significance $(F(2,39)=2.9 ; \mathrm{p}=0.06)$. Considering only patients with FSHD and control subjects, patients with FSHD had a significantly higher score (Fisher's test, $\mathrm{p}<0.05$ ) on the Tyrer scale.

\section{EMOTIONAL DIMENSIONS}

Emotional deficit, as an overall factor for the depressive mood scale, was significantly different for the three groups $(F(2,39)=6.41$; $\mathrm{p}=0.004)$ with the MD group scoring significantly higher than the two other groups.

A significant difference was found at the hypoexpressiveness end of the expressiveness range $(F(2,39)=8.19 ; \mathrm{p}=0.001)$. Patients with MD scored higher than both patients with FSHD and control subjects. ANOVA verged on significance for the anhedonia component of emotional deficit $(F(2,39)=2.86 ; \mathrm{p}=0.07)$, and showed a significant difference between patients with MD and control subjects (Fisher's test, $\mathrm{p}<0.05$ ).

These results were confirmed by the scores on the Abrams and Taylor scale for emotional blunting, which showed a significant difference between all three groups $(F(2,39)=7.26$; $\mathrm{p}=0.002)$. Emotional blunting was significantly greater in the MD group than the other two groups.

The factor called "loss of control" on the depressive mood scale did not show any significant difference either between the three groups $(F(2,39)=1.94 ; \mathrm{p}=0.16)$, or between its two components (irritability and hyperexpressiveness).

For the other two factors on the depressive mood scale, sadness was not significantly different for any of the three groups $(F(2,39)=2.38 ; \mathrm{p}=0.11)$, although patients with $\mathrm{MD}$ were slightly but significantly sadder than controls (Fisher's test, $\mathrm{p}<0.05$ ). The anxious hyperaesthesia factor did not differ significantly between the three groups studied.

ANHEDONIA

Self questionnaires on anhedonia showed a significant difference in physical anhedonia for the three groups studied $(F(2,37)=5.65$; $\mathrm{p}=0.008)$ but not in social anhedonia $(F(2,39)=2.29 ; \mathrm{p}=0.12)$. In the physical anhedonia questionnaire, patients with $\mathrm{MD}$ and patients with FSHD scored significantly higher than control subjects (Fisher's test, $\mathrm{p}<0.05$ ).

\section{Discussion}

Patients with MD in the present study were not severly depressed according to DSM III-R criteria, although they did present symptoms of mild depression. Patients with $\mathrm{MD}$ on the other hand had no symptoms of anxiety, whereas patients with FSHD presented significantly greater symptoms of depression and anxiety than control subjects. These results concur with those of Cuthill et $a l^{9}$ who found that although symptoms of depression were common in patients with $\mathrm{MD}$, few met the standard criteria for depression. Conversely, Brumback et $a l^{\beta}$ found a high incidence of major depressive episodes in the MD patient population studied.

In the literature there is a close association between depression and progressive diseases. ${ }^{26}{ }^{27}$ Duveneck et $a \bar{l}$ noted that this depressive symptomatology may arise through an emotional reaction to the disease. Patients with MD or other chronic diseases have to cope not only with physical restrictions and disabilities, but also with the financial and emotional ramifications of the disease; these may include loss of employment and income, lowered self esteem, and the possibility of a shortened life span. It is often difficult to clarify the origin of certain symptoms. Disturbances of sleep pattern (mostly hypersomnia), loss of appetite, and impaired memory and concentration are common in patients with neurological disease and whereas they may be symptoms of depression, they may also be related to the neurological disease itself. ${ }^{28-32}$

Duveneck et $a \bar{l}$ found that stress related symptoms and depressive reactions are common in multisystem diseases. Emotional disturbances-in particular emotional deficit ${ }^{19} 20$ - seem more common than typical depressive episodes. Patients with MD did, however, have a different emotional profile compared with FSHD and control subjects, with higher scores for emotional deficit. This deficit manifestated as anhedonia and lack of expressiveness as evidenced by a monotonous mood, apathy, and an inability to anticipate pleasure. The emotional pattern of negative symptoms as noted here is 
similar to the apathy and lack of motivation previously found in MD. ${ }^{1828}$ In the present study, these symptoms were not related to the presence of depression or anxiety. In fact, patients with MD with emotional deficit were neither depressed nor anxious, whereas the patients with FSHD who did not have emotional deficit were more depressed and anxious. A link may be seen between these results and the findings of the personality assessment. Four patients with MD displayed an avoidant personality disorder as opposed to none in the FSHD and control groups. ${ }^{33}$ Physical anhedonia was perceived in both patients with $M D$ and patients with FSHD, but social anhedonia was the same for all three groups. The anticipation of future physical disability in the two patient groups may account for the differences in the ratings of physical, but not social anhedonia. This suggests that it is important to make the distinction between physical and social anhedonia.

There are different hypotheses for the cause of these emotional disturbances (other than the process of psychological adaptation to the disease). There may be a genetic cause involved in this particular emotional process. Ambrosini et $a l^{4}$ considered these psychiatric phenomena as a primary aspect of the disease and as the direct pathogenesis of the neuromuscular condition. These authors present clinical evidence that altered mental functioning is a basic feature of $M D$, rather than a reactive or secondary phenomenon; they described MD as an extensive "multiple dystrophy". The CNS is a target, with specific neuropathology and psychopathology. In the present study, patients with MD were all in the early stages of the disease and, despite that, the CNS showed MRI abnormalities in nine patients. ${ }^{34}$ All patients with MD presented emotional deficit, whereas patients with FSHD, in whom the CNS is not affected, presented no deficit at all.

\section{Conclusion}

It seemed that patients with MD presented a characteristic emotional profile of emotional deficit, with the deficit appearing early in the disease and which could be interpreted as an adaptive psychological process or as a direct consequence of the CNS lesions caused by the genetic mutation. Close attention should be focused on these symptoms and their development and they should be taken into consideration in the care of chronic patients, because of the influence they have on their the physical and psychological wellbeing.

The present study has received support through a research grant from the French Myopathy Association (AFM). We thank Professor Bruno Eymard for referring the patients.

1 Rohrer K. Über Myotonia atrophica (dystrophica myotonica). Deutsche Zeitung von Nerven 1916;55:242-8.

2 Naegeli O. Über Myotonia atrophica, Speziell über die Symptome und die Pathogenses der Krankheit nach 22 eigenen Fallen. Munchen Medicine Wochenenschrift 1917;64: 1631 .
3 Rittmeister JF. Psychiche Befunde bei einem Geschlecht mit myotoner Dystrophie. Schweizer Archiv fur Neurologie Neurochirurgie und Psychiatrie 1939;43:329-59.

4 Ambrosini PJ, Nurnberg HG. Psychopathology: a primary feature of myotonic dystrophy. Psychosomatics 1979;20: 393-9.

5 Duveneck MJ, Portwood MM, Wicks JJ, et al. Depression in myotonic muscular dystrophy. Arch Phys Med Rehabil 1986;67:875-7.

6 Brumback RA, Carlson KM, Wilson H, et al. Myotonic dystrophy as disease of abnormal membrane receptors: hypothesis of pathophysiology and new approach to treatment. Med Hypotheses 1981;7:1059-66.

7 Bird TD, Follett C, Griep E. Cognitive and personality function in myotonic muscular dystrophy. 7 Neurol Neurosurg Psychiatry 1983;46:971-80.

8 Brumback RA. Disturbed personality and psychosocial adjustment in myotonic dystrophy: relationship to intellectual/cognitive function and underlying affective disorder (depression). Psychol Rep 1987;60:783-96.

9 Cuthill J, Gattereau A, Viguié F. Myotonic dystrophy of Steinert: are anxiety and depression necessarily concommittants. Can $\mathcal{F}$ Psychiatry 1988;33:203-6.

10 Colombo G, Perini GI, Miotti MV, et al. Cognitive and psychiatric evaluation of 40 patients with myotonic dystrophy. Ital 7 Neurol Sci 1992;13:53-8.

11 Mathieu J, De Braekeleer M, Prevost C, et al. Myotonic dystrophy: clinical assessment of muscular disability in an isolated population with presumed homogeneous mutation. Neurology 1992;42:203-8.

12 American Psychiatric Association. DSM III-R: Manuel diagnostique et statistique des troubles mentaux. In: Masson, ed. Traduction française par Pichot $P$ et Guelfi $F D$. Paris, 1989. Washington, DC: APA, 1939.

13 Montgomery SA, Asberg MA. A new depression scale designed to be sensitive to change. $\mathrm{Br} \mathcal{F}$ Psychiatry 1979;134:382-9.

14 Hamilton $M$. Development of a rating scale for primary depressive illness. British fournal of Social and Clincial Psychology 1967;6:278-96.

15 Lipman RS, Covi L, Downing RW. Pharmacotherapy of anxiety and depression: rationale and study design. Psychopharmacol Bull 1981;17:91-5.

16 Tyrer P, Owen RT, Cichetti DV. The brief scale for anxiety a subdivision of the comprehensive psychopathological rating scale. $\mathcal{F}$ Neurol Neurosurg Psychiatry 1984;47:970-5.

17 Abrams R, Taylor MA. A rating scale for emotional blunting. Am f Psychiatry 1978;135:226-9.

18 Jouvent R, Vindreau C, Montreuil M, et al. La clinique polydimensionnelle de l'humeur dépressive. Nouvelle version de l'échelle EHD. Psychiatr Psychobiol 1988;3:24553.

19 Bungener C, Jouvent R, Derouesné C. Affective disturbances in Alzheimer's disease. I Am Geriatr Soc 1996;44: 1066-71.

20 Bungener C, Lefrère JJ, Widlöcher D, et al. Emotional deficit: an adaptative and evolutive process in HIV deficit: an adaptative and evolutive proc
infection. Eur Psychiatry 1995;10:345-51.

21 Fawcett J, Clark DC, Scheftner WA, et al. Assessing anhedonia in psychiatric patients. Arch Gen Psychiatry 1983;40:79-84.

22 Loas G, Pierson A. L'Anhédonie en Psychiatrie: revue. Ann Méd-Psychol 1989;147:705-17.

23 Chapman LJ, Chapman JP, Raulin ML. Scales for physical and social anhedonia. F Abnorm Psychol 1976;85:374-82.

24 Loas G. Adaptation et validation française de l'échelle d'anhédonie physique de Chapman et Chapman. Physical Anhedonia Scale-PAS. Encephale 1993;19:639-44.

25 Kosmadakis C, Bungener C, Jouvent R, et al. Traduction et Validation de l'Echelle Révisée d'Anhédonie Sociale. Encephale 1995;21:437-43.

26 Levenson AI. Psychiatric aspects of AIDS. The Psychiatric Hospital 1988;3:109-13.

27 Mc Daniel JS, Musselman DL, Porter MR, et al. Depression in patients with AIDs. Dignosis, biology and treatment. Arch Gen Psychiatry 1995;52:89-99.

28 Granier F, Girard M, Schmitt L, et al. Manifestations Psychiatriques de la Maladie de Steinert. Ann Med Psychol (Paris) 1986;4:504-14.

29 Stolba R. Psychisches Stammhirnsyndrom bei Dystrophia myotonica. Confin in Neurologie 1947/48;8:185-211.

30 Kilburn KH, Eagan JT, Sicker HO. Cardiopulmonary insufficiency in myotonic and progressive muscular dystrophy. N Engl f Med 1959;261:1089-96.

31 Phemister JC, Small JM. Hypersomnia in dytrophia myotonica. F Neurol Neurosurg Psychiatry 1961;24:173-5.

32 Coccagna G, Mantovani M, Parchi C. Alveolar hypoventilation and hypersomnia in myotonic dystrophy. $\mathcal{F}$ Neurol Neurosurg Psychiatry 1975;38:977-84.

33 Delaporte C. Personality patterns in patients with myotonic dystrophy. Arch Neurol 1998 (in press).

34 Miaux Y, Chiras J, Eymard B, et al. Cranial MRI findings in myotonic dystrophy. Neuroradiology 1997;39:166-70. 